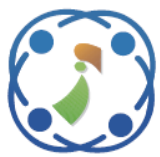

\title{
IoT Based Real-Time Monitoring of Phytoremediation of Wastewater using the Mathematical Model Implemented on the Embedded Systems
}

\author{
Evy Hendriarianti ${ }^{1}$ \\ Aryuanto Soetedjo ${ }^{2 *}$ \\ ${ }^{1}$ Department of Environmental Engineering, National Institute of Technology Malang, Indonesia \\ ${ }^{2}$ Department of Electrical Engineering, National Institute of Technology Malang, Indonesia \\ * Corresponding author’s Email: aryuanto@lecturer.itn.ac.id
}

\begin{abstract}
This paper presents the Internet of things (IoT) technology for real-time monitoring of wastewater phytoremediation. Phytoremediation is a technique to remove pollutants from the wastewater using the plants. A conventional method to monitor the phytoremediation performance is by taking the samples of the contaminants from a site and measuring them at the laboratory. This method needs many works for data preparation and analysis. A recent development on the IoT technology may eliminate such tasks by a real-time monitoring system. In the proposed realtime monitoring system, several phytoremediation models are implemented on embedded hardware and connected to the Thingspeak IoT platform. The proposed system aims to provide a real-time monitoring system to better model the phytoremediation by examining the monitoring data time interval and fitting techniques. From the experiments, the proposed monitoring system achieves a data transfer reliability of $81.4 \%$ when the period of the data transmission is one minute, which is suitable for one-day interval real-time monitoring system. The proposed monitoring system can build a phytoremediation model using a polynomial fitting with a higher fit than the existing methods using an exponential fitting. Further, the proposed method promises a better solution in terms of the best model, the low cost, and the acceptable accuracy.
\end{abstract}

Keywords: Phytoremediation, Internet of things, Mathematical model, Embedded systems.

\section{Introduction}

Wastewater treatment plays an essential task in daily activity in households and industrial plants. The wastewater from those activities is usually processed in a Wastewater Treatment Plant (WWTP), where the pollutant in the wastewater is removed, and the effluents are safe to discharge to the river. One approach to remove the contaminant from the wastewater is using the plants, which is called phytoremediation.

Many works [1-12] adopted phytoremediation in the wastewater treatment processes. Usually, they differ in the types of green plants and the pollutants to be removed. The water hyacinth was used in [1-5] as the plant for phytoremediation. The other types of plants are water lettuce [5], lettuce [6], kale [6-8], bamboo species [9], ornamental plant species [10], Rhizophora mangle [11], and Salvinia biloba [12].
Meanwhile, the common types of the pollutants to be removed are: $\mathrm{NO}_{3}[1,6,10], \mathrm{N}$ [2], $\mathrm{PO}_{4}$ [1], $\mathrm{Na}$ [3], $\mathrm{K}$ [3], $\mathrm{P}$ [4], $\mathrm{NH}_{3}$ [4, 6], $\mathrm{Zn} \mathrm{[5,} \mathrm{12],} \mathrm{Pb}[5,8,12], \mathrm{Fe}$ [5], $\mathrm{Cu}[5,9,12]$, Ni [5], Cd [7, 8, 12].

The effectiveness of phytoremediation is measured by the reduction of the pollutants such as biochemical oxygen demand (BOD), chemical oxygen demand (COD), total suspended solids (TSS), and total dissolved solids (TDS). Therefore, it requires to monitor those parameters regularly. The conventional method for monitoring the parameters is by collecting samples from the site and then measured at the laboratory every week, or every month or depending on the fund's availability. Furthermore, from the data collected, we could build a phytoremediation model for analyzing and predicting purposes.

A kinetic mathematical model of phytoremediation using water hyacinth was proposed 
in [2]. Authors in [2] employed a conceptual model using STELLA software to develop the system's various processes. The model focused on the nitrogen transformation in the phytoremediation process. Authors in [3] proposed a phytoremediation model to predict the trend of water hyacinth potential for the pulp and paper industry. The model was developed based on the exponential model of growth. The experimental data collected on the 15th, 30th, and 45 th days were utilized to verify the model.

There are a few works on the real-time monitoring of phytoremediation [13, 14]. In [13], the system was used to monitor the metal concentration in the plants by employing the reflectance spectroscopy and Laser Induced Breakdown Spectroscopy (LIB) sensors. In [14], a remote sensing technique using the satellite images was used to detect the heavy metal contained in the plants.

Most of the works for real-time monitoring the pollutants in the wastewater are developed to monitor the WWTP parameters, as discussed in the following. Online monitoring of the WWTP using Supervisory Control And Data Acquisition (SCADA) application was developed in $[15,16]$. SCADA system provides real-time monitoring of the WWTP parameters, such as $\mathrm{pH}, \mathrm{TSS}, \mathrm{DO}, \mathrm{COD}$ [15]. It is equipped with the alarm and the trending graphs of the important parameters of the WWTP. An advanced monitoring technique based-on the statistical method is added to detect the process fault [16].

A wastewater quality monitoring system using a website interface was developed in [17]. It consisted of a field monitoring system for collecting data from the sensors and the factory monitoring room where the webserver is located. An internet connection via $\mathrm{WiFi}$ is used to communicate between the field and the server.

The wastewater monitoring system using a LoRa technology was proposed in $[18,19]$. The LoRa enables a long-range communication of $20 \mathrm{Km}$ between the WWTPs and the gateway. Thus it provides a wide area monitoring of several WWTPs via the internet using a Geographical Information System (GIS)-based application.

WWTP monitoring systems using the Internet of Things (IoT) technology were proposed in [20-23]. A minimal model of IoT-based monitoring system was proposed in [20], where only three critical sensors, i.e., the temperature, turbidity, and $\mathrm{pH}$ sensors, were used to monitor the operational status of WWTP. Similar to [20], the three parameters of wastewater, namely the temperature, level, and flow, were considered in the monitoring system [21].

A low-cost sensor and IoT system to monitor the Electronic Conductivity, pH, Dissolved Oxygen,
Color, and Turbidity of the wastewater was proposed in [22]. A Thingspeak [23] was adopted as the IoT cloud server for displaying and analyzing the data.

Integration of Wireless Sensor Network (WSN) and IoT was proposed in [24] to perform a Decentralized Smart Water Quality Monitoring System. The sensor device employed a cost-effective optical sensor based-on an ion chromatography system [25] to detect nitrite and nitrate in the water. The sensor devices are easy to be deployed in multi WWTPs using WSN technology.

The online monitoring systems of the WWTP provide useful data for further processes and analyses. The advanced methods for analyzing the WWTP's monitored data were proposed in [26-28]. In [26], a sensor fault was detected from the monitored data using a fuzzy logic algorithm. It employed a TakagiSugeno fuzzy model to build an online fuzzy identification of the WWTP's non-linear processes. The deep learning techniques were adopted in [27, 28] for the fault detection of the WWTP. A deep neural network was proposed in [27] to detect the sensor fault by analyzing the oxidation and nitrification process's temporal data. The approach shows a high fault detection rate of $92 \%$. An unsupervised machine learning that integrates a deep belief network and a support vector machine was used in [28] for an anomaly-detection of decentralized WWTP.

In this paper, we propose a system to monitor the phytoremediation using IoT technology. Compared to the existing systems, our work has several distinctive approaches. First, compared to the conventional methods [1-12], our approach provides real-time monitoring of pollutant's concentration in the phytoremediation. Second, compared to the existing real-time monitoring in phytoremediation $[13,14]$, our approach offers a simple hardware configuration and adopts a recent IoT technology. Third, compared to the existing WWTP monitoring systems [15-28], our approach offers an efficient tool to monitor and examine the phytoremediation models by integrating the IoT platform and the mathematical model, which is implemented on the embedded hardware.

Instead of using the real WWTP, we develop realtime monitoring using a phytoremediation model which is implemented on an embedded system. Our previous work in [29] inspires the idea of using such a model for the real-time monitoring system. By implementing a phytoremediation model on embedded hardware, it could be connected to the IoT infrastructure for real-time monitoring. 
The rest of the paper is as follows. Section 2 presents our proposed system. Section 3 describes the results and discussion. Finally, the conclusion is covered in Section 4.

\section{Proposed system}

The configuration of the proposed system is illustrated in Fig. 1. It consists of three main parts: Phytoremediation models, WiFi Acces Point, and IoT cloud server. As shown in the figure, the phytoremediation models are implemented on the Arduino Nano 33 IoT modules [30]. In this work, we implement three phytoremediation models, where the models of Phytoremediation-1, Phytoremediation-2, and Phytoremediation-3 are adopted from [6,4,3], respectively.

Each phytoremediation model represents the concentration of the parameters of WWTP effluent for the phytoremediation period. The details of the models will be discussed in the following section.

In this work, we employ Thingspeak [23] as the IoT platform. Thanks to its compatibility with the Arduino module, the integration with the phytoremediation model could be easily performed. Since the Arduino Nano IoT is equipped with the WiFi module, it becomes a simple task to connect it to the internet via a WiFi Acces Point. The model's data is then sent to the Thingspeak cloud server at a specific time interval defined by the user configuration.

The Thingspeak provides an easy method to visualize and analyze the data on the cloud server that is collected from the field devices (Arduino Nano 33 IoT modules). In this way, the parameters of phytoremediation could be monitored in a real-time manner, and further analysis could be performed using the Thingspeak platform.

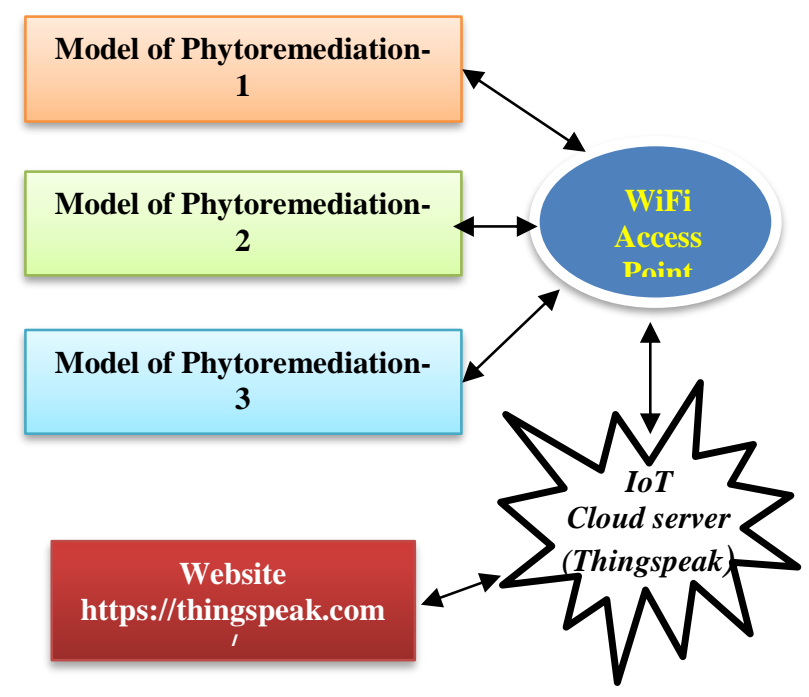

Figure. 1 System configuration

\subsection{Phytoremediation model}

A phytoremediation model used in this work is originated from the mathematical model proposed in [3]. In this model (hereafter called Exp-1 model), the phytoremediation potential at time $t\left(P_{t}\right)$ is expressed as

$$
P_{t}=P_{0} e^{\mu t}
$$

where $P_{0}$ is the phytoremediation potential at time $t=0$, and $\mu$ is the potential rate. The potential rate $(\mu)$ is defined by the following formula

$$
\begin{gathered}
\mu_{i}=\frac{\ln \left(\frac{P_{i}}{P_{0}}\right)}{t_{i}}, \\
\mu=\frac{\sum_{i=1}^{N} \mu_{i}}{N},
\end{gathered}
$$

where $i=1,2,3, \ldots N$; and $t_{i}$ is the time at interval $i$.

Using the above formulas, we may calculate or predict a pollutant's concentration in the phytoremediation at any time $t$. To build the model, we need to collect the data at several time intervals, e.g., $0,15,30$, and 45 days as proposed in [3]. Once the model is developed, then it could be implemented on the Arduino Nano 33 IoT module.

Even though the above model (Exp-1 model) [3] shows a reasonable accurate, from a few experiments, we find that the model cannot fit the other observed phytoremediation data indicated by the lower value of $\mathrm{R}^{2}$. Therefore we examine the other models as follows.

To provide a more general model, we evaluate the other models, i.e., an exponential model (hereafter called Exp-2 model) and a second-order polynomial model (hereafter called Poly model). The exponential model is expressed as

$$
P_{t}=a e^{b t}
$$

where $a, b$ are the parameters that are calculated using the least square method. The second-order polynomial model is expressed as

$$
P_{t}=a_{0}+a_{1} t+a_{2} t^{2}
$$

where $a_{0}, a_{1}, a_{2}$ are the parameters that are calculated using the least square method.

Eqs. (1)-(5) are used to build the Phytoremediation Model-1, Phytoremediation Model-2, and Phytoremediation Model-3 as described in the following. 
Table 1. Observed data of the Phytoremediation-1

\begin{tabular}{|l|l|l|l|l|}
\hline \multirow{2}{*}{ Plant } & \multirow{2}{*}{$\begin{array}{l}\text { Monitored } \\
\text { parameter }\end{array}$} & \multicolumn{3}{|c|}{ Observed data (mg/L) } \\
\cline { 3 - 5 } & & Day=0 & Day=7 & Day=14 \\
\hline \multirow{2}{*}{ Kale } & $\mathrm{NH}_{3}$ & 6.965 & 5.560 & 1.479 \\
\cline { 2 - 5 } & $\mathrm{NO}_{3}$ & 15.940 & 15.570 & 7.935 \\
\hline \multirow{2}{*}{ Lettuce } & $\mathrm{NH}_{3}$ & 8.200 & 9.260 & 33.000 \\
\cline { 2 - 5 } & $\mathrm{NO}_{3}$ & 5.822 & 9.072 & 10.120 \\
\hline
\end{tabular}

Table 2. Observed data of the Phytoremediation-2

\begin{tabular}{|l|l|l|l|l|}
\hline \multirow{2}{*}{ Plant } & \multirow{2}{*}{$\begin{array}{l}\text { Monitored } \\
\text { parameter }\end{array}$} & \multicolumn{3}{|l|}{ Observed data (mg/L) } \\
\cline { 3 - 5 } & & Day=0 & Day=7 & Day=14 \\
\hline \multirow{2}{*}{ A. pinnata } & $\mathrm{NH}_{3}$ & 8.00 & 4.85 & 2.26 \\
\cline { 2 - 5 } & $\mathrm{P}$ & 1.00 & 0.96 & 0.39 \\
\hline \multirow{2}{*}{$\begin{array}{l}\text { E. } \\
\text { crassipes }\end{array}$} & $\mathrm{NH}$ & 8.00 & 5.23 & 2.74 \\
\cline { 2 - 5 } & $\mathrm{P}$ & 1.00 & 0.99 & 0.5 \\
\hline
\end{tabular}

Table 3. Observed data of the Phytoremediation-3

\begin{tabular}{|l|l|l|l|l|l|}
\hline Plant & \multirow{2}{*}{$\begin{array}{l}\text { Monitored } \\
\text { parameter }\end{array}$} & \multicolumn{4}{|c|}{ Observed data (ppm) } \\
\cline { 3 - 6 } & & Day=0 & Day= 15 & $\begin{array}{l}\text { Day=3 } \\
0\end{array}$ & Day=45 \\
\hline \multirow{4}{*}{$\begin{array}{l}\text { E. } \\
\text { crassipes }\end{array}$} & TSS & 406.7 & 279.3 & 191.3 & 132 \\
\cline { 2 - 6 } & $\mathrm{COD}$ & 800 & 497.4 & 309.3 & 192 \\
\cline { 2 - 6 } & $\mathrm{Na}$ & 19.3 & 16.4 & 13.9 & 11.9 \\
\cline { 2 - 6 } & $\mathrm{K}$ & 39.4 & 32.6 & 26.8 & 22.3 \\
\hline
\end{tabular}

The observed data and the monitored parameters of the Phytoremediation-1, Phytoremediation-2, and Phytoremediati-3 are listed in Table 1, Table 2, and Table 3 , respectively.

The Phytoremediation-1 model represents the phytoremediation of the Tlogomas Communal WWTP in Malang City, Indonesia [6]. The monitored parameters are Ammonia $\left(\mathrm{NH}_{3}\right)$ and Nitrate $\left(\mathrm{NO}_{3}\right)$, while the phytoremediation plants are the Kale (Ipomoea aquatic) and the Lettuce (Lactuca sativa L.).

The Phytoremediation-2 model represents the phytoremediation of wastewater from Estero de San Miguel Mendiola, Manila, Philippines [4]. The monitored parameters are Ammonia $\left(\mathrm{NH}_{3}\right)$ and Phosphorous (P), while the phytoremediation plants are the Azolla pinnata and Eichhornia crassipes.

The Phytoremediation-3 model represents the phytoremediation of wastewater from the Century Pulp and Paper Industry, Lalkuan, India [3]. The monitored parameters are TSS, COD, Natrium (Na), and Kalium $(\mathrm{K})$, while the phytoremediation plant is the water hyacinth (Eichhornia crassipes).

We evaluate each phytoremediation model using the Eqs. (1) - (5). Since the minimum time interval of observed data listed in Table 1 to Table 3 is seven days, we create a linear interpolation model (hereafter
Table 4. Mathematical model of the phytoremediation-1

\begin{tabular}{|c|c|c|c|c|c|}
\hline \multirow{3}{*}{\multicolumn{2}{|c|}{$\begin{array}{l}\text { Model } \\
\text { name }\end{array}$}} & \multicolumn{4}{|c|}{ Mathematical model } \\
\hline & & \multicolumn{2}{|l|}{ Kale } & \multicolumn{2}{|l|}{ Lettuce } \\
\hline & & $\mathrm{NH}_{3}$ & $\mathrm{NO}_{3}$ & $\mathrm{NH}_{3}$ & $\mathrm{NO}_{3}$ \\
\hline \multirow{2}{*}{ Lin } & $\begin{array}{l}\text { Day: } \\
0-7\end{array}$ & $\begin{array}{l}-0.2007 t \\
+6.965 \\
\end{array}$ & $\begin{array}{l}-0.0528 t \\
+15.94\end{array}$ & $\begin{array}{l}0.1514 t \\
+8.2\end{array}$ & $\begin{array}{l}0.4643 t \\
+5.822\end{array}$ \\
\hline & $\begin{array}{l}\text { Day: } \\
\text { 8-14 }\end{array}$ & $\begin{array}{r}-0.583 t \\
+9.641 \\
\end{array}$ & $\begin{array}{l}-1.0907 t \\
+23.205\end{array}$ & $\begin{array}{c}3.3914 t \\
-14.48\end{array}$ & $\begin{array}{l}0.1497 t \\
+8.024\end{array}$ \\
\hline \multicolumn{2}{|c|}{ Exp-1 } & $\begin{array}{l}6.965 \\
e^{-0.0714 t}\end{array}$ & $\begin{array}{l}15.940 \\
e^{-0.0266 t}\end{array}$ & $\begin{array}{l}8.200 \\
e^{0.0584 t}\end{array}$ & $\begin{array}{l}5.822 \\
e^{0.0514 t}\end{array}$ \\
\hline \multicolumn{2}{|c|}{ Exp-2 } & $\begin{array}{c}8.365 \\
e^{-0.111 t}\end{array}$ & $\begin{array}{l}17.766 \\
e^{-0.05 t}\end{array}$ & $\begin{array}{l}6.7706 \\
e^{0.0995 t}\end{array}$ & $\begin{array}{l}6.1555 \\
e^{0.0395 t}\end{array}$ \\
\hline \multicolumn{2}{|c|}{ Poly } & $\begin{array}{c}-0.0273 t^{2} \\
-0.0096 t \\
+6.965\end{array}$ & $\begin{array}{l}-0.0741 t^{2} \\
+0.4661 t \\
+15.94\end{array}$ & $\begin{array}{l}0.2314 t^{2} \\
-1.4686 t \\
+8.2\end{array}$ & $\begin{array}{l}-0.0225 t^{2} \\
+0.6216 t \\
+5.822\end{array}$ \\
\hline
\end{tabular}

Table 5. Mathematical model of the phytoremediation-2

\begin{tabular}{|c|c|c|c|c|c|}
\hline \multirow{3}{*}{\multicolumn{2}{|c|}{$\begin{array}{l}\text { Model } \\
\text { name }\end{array}$}} & \multicolumn{4}{|c|}{ Mathematical model } \\
\hline & & \multicolumn{2}{|c|}{ A. pinnata } & \multicolumn{2}{|c|}{ E. crassipes } \\
\hline & & $\mathrm{NH}_{3}$ & $P$ & $\mathrm{NH}_{3}$ & $P$ \\
\hline \multirow{2}{*}{ Lin } & $\begin{array}{l}\text { Day: } \\
0-7\end{array}$ & $\begin{array}{l}-0.45 t \\
+8\end{array}$ & $\begin{array}{l}-0.0057 t \\
+1\end{array}$ & $\begin{array}{l}-0.3957 t \\
+8\end{array}$ & $\begin{array}{l}-0.0014 t \\
+1\end{array}$ \\
\hline & $\begin{array}{l}\text { Day: } \\
8-14\end{array}$ & $\begin{array}{l}-0.37 t \\
+7.44\end{array}$ & $\begin{array}{l}-0.0814 t \\
+1.53\end{array}$ & $\begin{array}{l}-0.3557 t \\
+7.72\end{array}$ & $\begin{array}{l}-0.07 t \\
+1.48\end{array}$ \\
\hline \multicolumn{2}{|c|}{ Exp-1 } & $8 e^{-0.08089 t}$ & $1 e^{-0.0365 t}$ & $8 e^{-0.0686 t}$ & $1 e^{-0.0255 t}$ \\
\hline \multicolumn{2}{|c|}{ Exp-2 } & $\begin{array}{l}8.3587 \\
e^{-0.09 t}\end{array}$ & $\begin{array}{l}1.1541 \\
e^{-0.067 t}\end{array}$ & $\begin{array}{l}8.3007 \\
e^{-0.077 t}\end{array}$ & $\begin{array}{l}1.1187 \\
e^{-0.05 t}\end{array}$ \\
\hline \multicolumn{2}{|c|}{ Poly } & $\begin{array}{l}0.0057 t^{2} \\
-0.49 t \\
+8\end{array}$ & $\begin{array}{l}-0.0054 t^{2} \\
+0.0321 t \\
+1\end{array}$ & $\begin{array}{l}0.0029 t^{2} \\
-\quad 0.4157 t \\
+8\end{array}$ & $\begin{array}{l}-0.0049 t^{2} \\
+0.0329 t \\
+1\end{array}$ \\
\hline
\end{tabular}

Table 6. Mathematical model of the phytoremediation-3

\begin{tabular}{|c|c|c|c|c|c|}
\hline \multirow{2}{*}{\multicolumn{2}{|c|}{$\begin{array}{l}\text { Model } \\
\text { name }\end{array}$}} & \multicolumn{4}{|c|}{ Mathematical model } \\
\hline & & TSS & COD & $\mathrm{Na}$ & $\mathrm{K}$ \\
\hline \multirow{3}{*}{ Lin } & $\begin{array}{l}\text { Day: } \\
0-15\end{array}$ & $\begin{array}{l}-8.4933 t \\
+406.7\end{array}$ & $\begin{array}{l}-20.1733 t \\
+800\end{array}$ & $\begin{array}{l}-0.1933 t \\
+19.3\end{array}$ & $\begin{array}{l}-0.4533 t \\
+39.4\end{array}$ \\
\hline & $\begin{array}{l}\text { Day: } \\
16-30\end{array}$ & $\begin{array}{l}-5.8667 t \\
+367.3\end{array}$ & $\begin{array}{l}-12.54 t \\
+685.5 \\
\end{array}$ & $\begin{array}{l}-0.1667 t \\
+18.9\end{array}$ & $\begin{array}{l}-0.3867 t \\
+38.4\end{array}$ \\
\hline & $\begin{array}{l}\text { Day: } \\
31-45\end{array}$ & $\begin{array}{l}-3.9533 t \\
+309.9 \\
\end{array}$ & \begin{tabular}{|l|}
$-7.82 t$ \\
+543.9 \\
\end{tabular} & $\begin{array}{l}-0.1333 t \\
+17.9\end{array}$ & $\begin{array}{l}-0.0108 t \\
+27.12\end{array}$ \\
\hline \multicolumn{2}{|c|}{ Exp-1 } & $\begin{array}{l}406.7 \\
e^{-0.02507 t}\end{array}$ & $\begin{array}{l}800 \\
e^{-0.03169 t}\end{array}$ & $\begin{array}{l}19.3 \\
e^{-0.01085 t}\end{array}$ & $\begin{array}{l}39.4 \\
e^{-0.01271 t}\end{array}$ \\
\hline \multicolumn{2}{|c|}{ Exp-2 } & $\begin{array}{l}406.42 \\
e^{-0.025 t}\end{array}$ & $\begin{array}{l}800.25 \\
e^{-0.032 t}\end{array}$ & $\begin{array}{l}19.276 \\
e^{-0.011 t}\end{array}$ & $\begin{array}{l}39.381 \\
e^{-0.013 t}\end{array}$ \\
\hline \multicolumn{2}{|c|}{ Poly } & $\begin{array}{l}0.0757 t^{2} \\
-\quad 9.4857 t \\
+406.17 \\
\end{array}$ & $\begin{array}{l}0.2059 t^{2} \\
-\quad 22.679 t \\
+797.82 \\
\end{array}$ & $\begin{array}{l}0.001 t^{2} \\
-\quad 0.2097 t \\
+19.305 \\
\end{array}$ & $\begin{array}{l}0.0026 t^{2} \\
-\quad 0.4957 t \\
+39.415 \\
\end{array}$ \\
\hline
\end{tabular}

called Lin model) between these intervals to provide daily data.

The Lin, Exp-1, Exp-2, and Poly models of the Phytoremediation-1, Phytoremediation-2, and Phytoremediation- 3 are given in Table 4 , Table 5, and Table 6, respectively. These mathematical models were then implemented on the Arduino Nano 33 IoT 
for real-time monitoring using the Thingspeak platform.

\subsection{Thingspeak configuration}

The objective of applying the IoT technology in phytoremediation is to monitor the parameters in a real-time manner. By performing real-time monitoring, the data can be collected hourly or daily. Thus data can be analyzed accurately.

In this work, we configure the Thingspeak to accomplish those objectives, especially in terms of data visualization and analysis. Fortunately, both features are supported by Thingspeak, specifically the integration of Thingspeak and Matlab [31] for the data analysis. Thus the modeling, i.e., the data fitting, could be performed easily.

As described previously, the period for manual data collecting in the phytoremediation is usually seven days (one week). It suggests that for better monitoring, the period for real-time monitoring could be conducted in one day. For simplification and evaluation purposes, we configure the phytoremediation model (Arduino Nano 33 IoT) to send the data to the Thingspeak every minute that reflects every day in the real phytoremediation process.

Table 7. Evaluation scenario

\begin{tabular}{|l|l|l|}
\hline \multirow{2}{*}{ No. } & Model name \\
\cline { 2 - 3 } & Period=1 min & Period=7 min \\
\hline 1 & NA & Observed data \\
\hline 2 & Lin model & NA \\
\hline 3 & Exp-1 model & Exp-1 model \\
\hline 4 & Exp-2 model & Exp-2 model \\
\hline 5 & Poly model & Poly model \\
\hline \multicolumn{2}{|c}{ 15 min for Phytoremediation-3 } \\
\hline
\end{tabular}

Table 8. Time slot of data transfer and analysis

\begin{tabular}{|l|l|}
\hline $\begin{array}{l}\text { Time } \\
\text { slot }\end{array}$ & Data transfer allocation ${ }^{\#}$ \\
\hline 0h & Lin model, 1 min interval: 0 - 14 \\
\hline 1h & Exp-1 model, 1 min interval: 0 - 14 \\
\hline 2h & Exp-2 model, 1 min interval: 0 - 14 \\
\hline 3h & Poly model, 1 min interval: 0 - 14 \\
\hline 4h & Observed data, 7 min interval: $0,7,14$ \\
\hline $5 \mathrm{~h}$ & Exp-1 model, 7 min interval: $0,7,14$ \\
\hline $6 \mathrm{~h}$ & Exp-2 model, 7 min interval: $0,7,14$ \\
\hline $7 \mathrm{~h}$ & Poly model, 7 min interval: $0,7,14$ \\
\hline
\end{tabular}

- Phytoremediation-1 \&2: $7 \mathrm{~min}$ period $=0,7,14$

- Phytoremediation-3: $15 \mathrm{~min}$ period $=0,15,30,45$
To evaluate our proposed system, we prepare five scenarios, as shown in Table 7, where each scenario differs in the data transfer period, and the model used. It is noted here that the Observed data is only available for $7 \mathrm{~min}$ period, and the Lin model is only available for $1 \mathrm{~min}$ period. Since the maximum time required by the phytoremediation model (Phytoremiation-3) is $45 \mathrm{~min}$, we allocate each scenario in the one-hour time slot in the Thingspeak as given in Table 8 .

\section{Results and discussion}

In the experiments, we implement the phytoremediation models on the embedded hardware (Arduino Nano 33 IoT) according to the scenario given in previous section. Then we run and connect the modules to the internet.

To evaluate the proposed system, we examine the data transfer between the Arduino modules and the Thingspeak cloud server, and the data fitting (modeling) performed by the Thingspeak (and Matlab). Further, the comparison with the existing methods is also conducted. The evaluation results are described in the following.

\subsection{Evaluation of data transfer}

The objective of the evaluation of the data transfer is to analyze the performance of the proposed IoT system in transferring the data. It includes the data transfer time interval, the data transfer reliability, and the data visualization.

The data transfer time interval (DTI) is defined as the time interval between the data received by the Thingspeak. Since the Arduino module sends the data on a specific period (see Table 7), the DTI can measure the inter-data transmission's delay time to the Thingspeak. The DTI is calculated by averaging the time interval at every time slot from observing the timestamps data in the Thingspeak, i.e., the duration of data received divided by the number of data received during the one-hour time slot. A good transmission is achieved when the DTI is the same as the period of data sent from the Arduino module.

The data transfer reliability (DTR) is defined as the success rate of the data received by Thingspeak. The DTR is calculated as the ratio of the number of data received by the Thingspeak to the number of data sent by the Arduino module at each time slot. A high DTR's value (maximum is $100 \%$ ) indicates a good data transfer.

The DTI and DTR of each phytoremediation model are given in Table 9. From the table, it is obtained that the DTIs of 7 min and 15 min periods are similar to their periods. However, the DTI of a 1 
Table 9. Data transfer time interval and reliability

\begin{tabular}{|l|l|l|l|l|}
\hline \multirow{2}{*}{$\begin{array}{l}\text { Phytoremediation } \\
\text { model }\end{array}$} & \multicolumn{2}{|l|}{$\begin{array}{l}\text { Period= } \\
1 \mathrm{~min}\end{array}$} & \multicolumn{2}{|l|}{$\begin{array}{l}\text { Period } \\
7(15)\end{array}$} \\
\cline { 2 - 6 } & $\begin{array}{l}\text { DTI } \\
(\mathrm{min})\end{array}$ & $\begin{array}{l}\text { DTR } \\
(\%)\end{array}$ & $\begin{array}{l}\text { DTI } \\
(\min )\end{array}$ & $\begin{array}{l}\text { DTR } \\
(\%)\end{array}$ \\
\hline Phytoremediation-1 & 1.2 & 85 & 7 & 100 \\
\hline Phytoremediation-2 & 1.57 & 73.33 & 7 & 100 \\
\hline Phytoremediation-3 & 1.18 & 85.87 & 15 & 87.5 \\
\hline Total average & 1.317 & 81.4 & $7(15)$ & 95.83 \\
\hline
\end{tabular}

min period is greater than its period (1 min). By observing the DTR and due to the DTI is the average time interval at each time slot, the longer value of DTI is caused by the lower value of DTR, in the sense that since the Thingspeak receives only $81.4 \%$ of the data sent by the Arduino module, thus the average value of the time interval becomes higher than $1 \mathrm{~min}$. The result means that the system could not perform well for transferring data at a period of $1 \mathrm{~min}$. It may be caused by the internet connection between the access point and the Thingspeak server. The result also suggests that the system performs well at a period of $7 \mathrm{~min}$. It means that the longer period is better for data transmission. Thus for a real

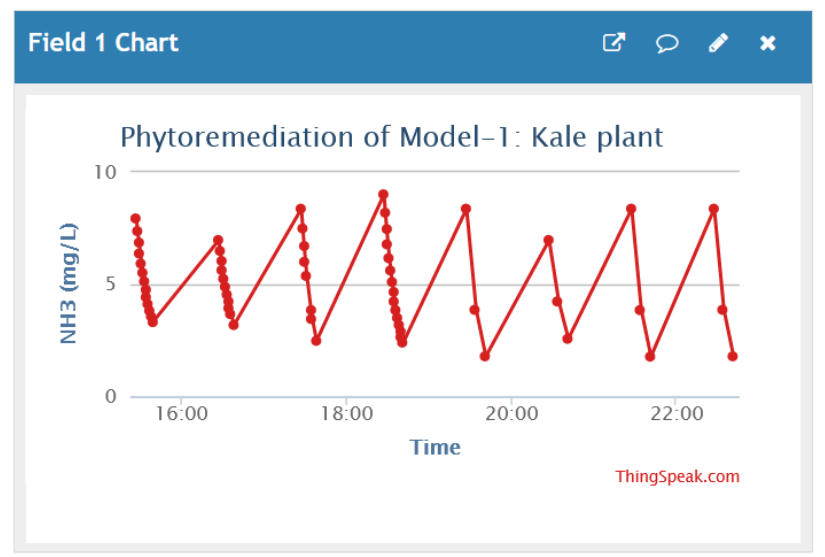

(a)

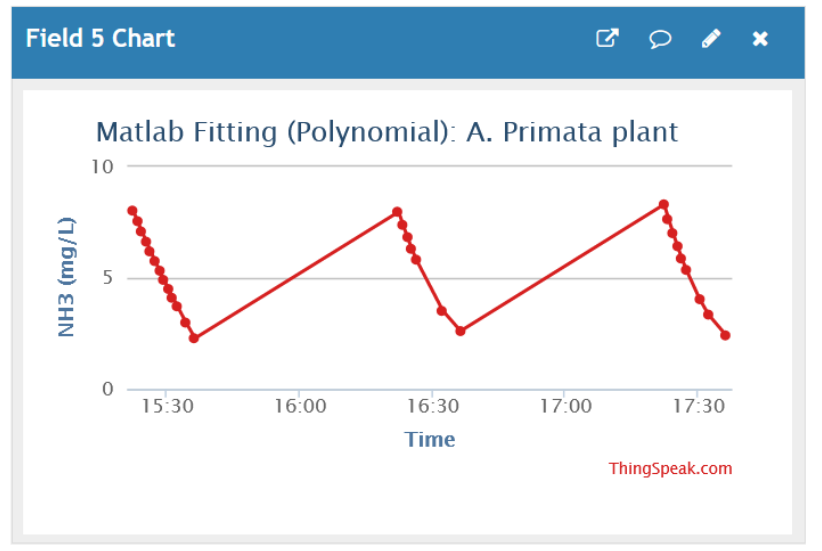

(b)

Figure. 2 Data visualization: (a) phytoremediation model and (b) thingspeak (Matlab) fitting implementation, an hour period of real-time monitoring could be accomplished by the proposed system.

The examples of data visualization in the Thingspeak are shown in Fig. 2, where Fig. 2 (a) shows the data visualization of the phytoremediation model sent by the Arduino module, while Fig. 2 (b) shows the data visualization of the data fitting performed by Thingspeak (Matlab).

From Fig. 2 (a), we can see the visualization of the model for the time slot given in Table 8 . The first four hours on the left are the models from the time slot of $0 \mathrm{~h}$ to $3 \mathrm{~h}(15: 30 \mathrm{~h}$ to $18: 30 \mathrm{~h}$ in the figure), where the period is $1 \mathrm{~min}$. It is clearly shown here that some data points are missing as described previously. While the models of $7 \mathrm{~min}$ period are shown on the right side (19:30h to $21: 30 \mathrm{~h}$ ), where only three data points are received at each time slot. From Fig. 2 (b), we can see that Thingspeak is able to fit the received data properly, even though some data are missing.

\subsection{Evaluation of data fitting}

The data fitting evaluation objectives are to verify the data fitting techniques performed by Thingspeak and find the best data fitting technique. The coefficient of determination $\left(\mathrm{R}^{2}\right)$ is used as the evaluation criteria, where the higher value indicates the goodness of fitting.

In this work, the data fitting techniques used by the Thingspeak are the exponential model (Exp-2) and the second-order polynomial model (Poly). For the evaluation, we configure the Thingspeak to apply both data fitting techniques using the five scenarios given in Table 7. The evaluation results are given in Table 10.

Referring to Table 10, we obtain several findings as follows:

- In the Phytoremediation-1 and Phytoremediation-2, the Poly model achieves better fitting than the Exp- 2 model for both 1 min and 7 min periods. It is also shown that even though the data on the Arduino modules are built using the Exp-1 and Exp-2 models, the Poly models performed by the Thingspeak achieve the high values of 0.999. Meanwhile, when the Poly models are built in the Arduino, the Exp-2 models performed by the Thingspeak only achieve values about 0.8 .

- In the Phytoremediation-3, both the Exp-2 and Poly models show similar results, i.e., $\mathrm{R}^{2}=0.999$. It means that both fitting techniques are suitable for the monitored data in the Phytoremediation3. 
Table 10. Data fitting evaluation

\begin{tabular}{|c|c|c|c|c|}
\hline \multirow{2}{*}{\begin{tabular}{c} 
Phytoremediation $\begin{array}{c}\text { model } \\
\text { Implemented Arduino } \\
\text { module) }\end{array}$ \\
\cline { 2 - 5 }
\end{tabular}} & \multicolumn{3}{|c|}{$\begin{array}{c}\text { Period= } \\
1 \text { min }\end{array}$} & \multicolumn{2}{c|}{$\begin{array}{c}\text { Period } \\
\text { (15) min }\end{array}$} \\
\cline { 2 - 5 } & Exp-2 & Poly & Exp-2 & Poly \\
\hline Phytoremediation-1 & & & & \\
\hline Observed data & NA & NA & 0.817 & 1 \\
\hline Lin model & 0.851 & 0.993 & NA & NA \\
\hline Exp-1 model & 1 & 0.999 & 1 & 1 \\
\hline Exp-2 model & 1 & 0.999 & 1 & 1 \\
\hline Poly model & 0.844 & 1 & 0.817 & 1 \\
\hline Average-1 & 0.924 & 0.998 & 0.909 & 1 \\
\hline Phytoremediation-2 & & & & \\
\hline Observed data & NA & NA & 0.833 & 1 \\
\hline Lin model & 0.840 & 0.993 & NA & NA \\
\hline Exp-1 model & 1 & 0.999 & 1 & 1 \\
\hline Exp-2 model & 1 & 0.999 & 1 & 1 \\
\hline Poly model & 0.851 & 1 & 0.831 & 1 \\
\hline Average-2 & 0.923 & 0.998 & 0.916 & 1 \\
\hline Phytoremediation-3 & & & & \\
\hline Observed data & NA & NA & 0.999 & 0.999 \\
\hline Lin model & 0.981 & 0.997 & NA & NA \\
\hline Exp-1 model & 1 & 0.999 & 0.999 & 0.999 \\
\hline Exp-2 model & 1 & 0.999 & 0.999 & 0.999 \\
\hline Poly model & 0.999 & 0.999 & 1 & 1 \\
\hline Average-3 & 0.995 & 0.999 & 0.999 & 0.999 \\
\hline Total Average & 0.947 & 0.998 & 0.941 & 0.999 \\
\hline
\end{tabular}

- By examining the three phytoremediation models' average values, it can be concluded that the polynomial fitting provides a better model than the exponential fitting.

Comparing the results of $1 \mathrm{~min}$ period and $7 \mathrm{~min}$ (or $15 \mathrm{~min}$ ) periods, it is obtained that the $\mathrm{R}^{2}$ of both periods are almost the same. It is worth noting here that even though the data transfer reliability of a 1 min period is $81.4 \%$ (see Table 9), it is able to build a model with good fitting.

The comparison results of the data fitting are illustrated in Figs. 3 and Fig. 4. Fig. 3 shows the data fitting of the Phytoremediation-1, where the plant is the Kale, the pollutant is $\mathrm{NO}_{3}$, and the data transfer period is $7 \mathrm{~min}$. In the figure, the blue, red, and purple lines represent the Observed data, the Exp-2 model (Thingspeak), and the Poly model (Thingspeak), respectively. It is clearly shown that the Poly model is better fitting than the Exp-2 model.

Fig. 4 shows the data fitting of the Phytoremediation-2, where the plant is the E. crassipes, the pollutant is $\mathrm{P}$, and the data transfer period is $1 \mathrm{~min}$. In the figure, the blue, aqua, orange,

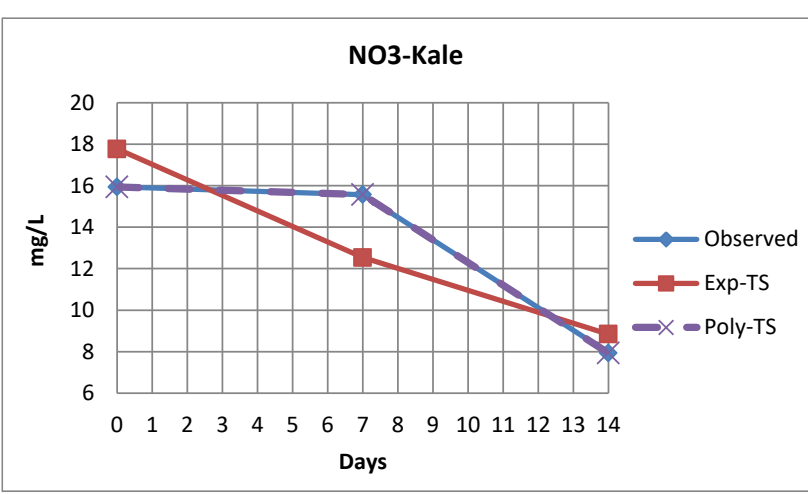

Figure. 3 Data fitting of phytoremediation-1 (7 min period)

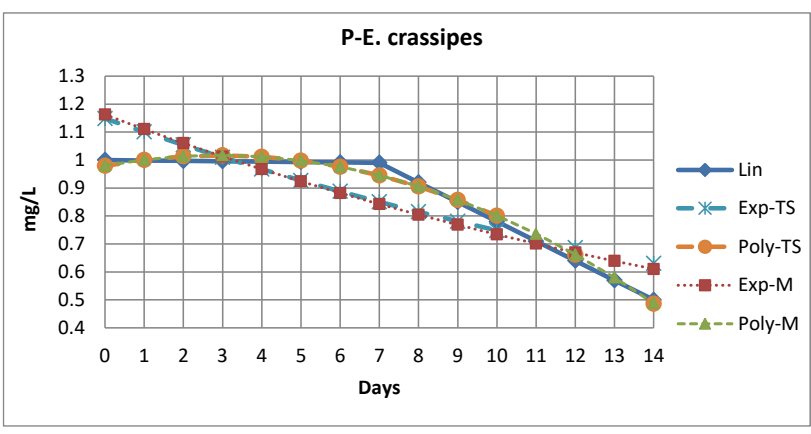

Figure. 4 Data fitting of phytoremediation-2 (1 min period)

red, and green lines represent the Lin model, the Exp-2 model (Thingspeak), the Poly model (Thingspeak), the Exp-2 model (Arduino), and the Poly model (Arduino), respectively. It is clearly shown that the Poly model is better fitting than the Exp-2 model. The figure also shows that the model obtained by the Thingspeak is similar to the Arduino.

\subsection{Comparison with the existing methods}

The comparison with the existing methods is conducted by evaluating the models' goodness, the measurement system accuracy, and the total cost. Comparing the goodness of fitting of the models is obtained from the previous section and is given in Table 11. In the table, the existing method (Ext) uses the existing data time interval of 7 days for the Phytoremediation-1 and Phytoremediation-2, and 15 days for the Phytoremediation-3, and the exponential model (Exp-2) for data fitting. The proposed method (Prop) uses the data time interval of 1 day (interpolated from the existing data using the Lin model), and the polynomial model (Poly) for data fitting.

Table 11 shows that the Prop achieves a higher $\mathrm{R}^{2}$ than the Ext in the Phytoremediation-1 and Phytoremediation-2 and almost the same as Ext for the Phytoremediation-3. From the table, it is obtained 
Table 11. Comparison of the goodness of the model

\begin{tabular}{|l|l|l|}
\hline \multirow{2}{*}{ Phytoremediation } & \multicolumn{2}{|l|}{$\mathrm{R}^{2}$} \\
\cline { 2 - 3 } & Ext & Prop \\
\hline Phytoremediation-1 [6] & 0.817 & 0.993 \\
\hline Phytoremediation-2 [4] & 0.833 & 0.993 \\
\hline Phytoremediation-3 [3] & 0.999 & 0.997 \\
\hline Average & 0.883 & 0.994 \\
\hline
\end{tabular}

Table 12. Comparison of the accuracy and cost

\begin{tabular}{|l|l|l|}
\hline & Ext & Prop \\
\hline 1. Measurement accuracy & $98 \%$ & $95 \%$ \\
\hline 2. Cost & & \\
\hline a. Initial cost & NA & USD 640 \\
\hline b. Measurement cost per day & USD 50 & USD 0.5 \\
\hline c. Total cost-A (Day=0,7,14) & USD 150 & USD 641.5 \\
\hline d. Total cost-B Day=0 - 14) & USD 750 & USD 647.5 \\
\hline
\end{tabular}

that the average value of $\mathrm{R}^{2}$ of the Prop is higher than the Ext. It means that our proposed method provides a better model compared to the existing ones.

To compare the measurement accuracy and the total cost, we evaluate the Phytoremediation-1 [6] only due to the accuracy and cost data availability. The comparison results are given in Table 12. Since the pollutants' concentration is measured at the laboratory in the Ext, the accuracy of the spectrophotometric method is measured. While in the Prop, the accuracy of the ion-selective electrode sensor is measured. As shown in the table, the accuracy of the Prop is slightly lower than the Ext.

The cost shown in Table 12 is described in the following. The initial cost is the cost for the sensors and IoT systems installation. Thus it is applicable for the Prop only. The measurement cost per day is a daily cost for conducting the data collection and measurement. In the Ext, it consists of the labor and accommodation costs for collecting data on the site and the measurement cost at the laboratory. In the Prop, the measurement cost is the data communication (internet) subscription fee. The total cost-A is the total cost when the measurement is conducted in a 7 days interval (the day of $0^{\text {th }}, 7^{\text {th }}$, and $\left.14^{\text {th }}\right)$. The total cost-B is the total cost when the measurement is conducted every day (the day of $0^{\text {th }}$ to $\left.14^{\text {th }}\right)$. It is obtained from the table that the total cost-A of the Prop is higher than the Ext. However, the total cost-B of the Prop is lower than the Ext.

The above results suggest that for one-day interval monitoring system, our proposed method promises a better solution in terms of the best model, the low cost, and the acceptable accuracy.

\section{Conclusion}

Real-time monitoring of the phytoremediation using the Thingspeak IoT platform is proposed. The IoT system is connected to the embedded hardware, where the mathematical model of the phytoremediation is implemented. Several phytoremediation models could be developed and monitored in real-time using the IoT application using the proposed system. The data transfer evaluation yields the average data transfer time interval of $1.317 \mathrm{~min}, 7 \mathrm{~min}$, and $15 \mathrm{~min}$ when the data transfer periods are $1 \mathrm{~min}, 7 \mathrm{~min}$, and $15 \mathrm{~min}$, respectively. The average data transfer reliability is $81.4 \%$ and $95.83 \%$ when the data transfer periods are $1 \mathrm{~min}$ and $7 \mathrm{~min}$ (and $15 \mathrm{~min}$ ), respectively. The evaluation of data fitting shows that a polynomial model achieves better fit than the exponential model. Further, the proposed one-day interval real-time monitoring system promises an acceptable accuracy with a lower cost than the existing methods.

In the future, the implementation of the monitoring system on the real phytoremediation plant will be conducted. Further, advanced data analysis techniques will be developed to address the real application.

\section{Conflicts of Interest}

The authors declare no conflict of interest.

\section{Author Contributions}

"Conceptualization, E. Hendriarianti and A. Soetedjo; methodology, E. Hendriarianti and A. Soetedjo; software, A. Soetedjo; validation, E. Hendriarianti and A. Soetedjo; formal analysis, E. Hendriarianti and A. Soetedjo; data curation, E. Hendriarianti and A. Soetedjo; writing-original draft preparation, A. Soetedjo; writing - review and editing, E. Hendriarianti and A. Soetedjo; visualization, A. Soetedjo; project administration, E. Hendriarianti.

\section{Acknowledgments}

This work was supported by the National Institute of Technology (ITN) Malang Research Grant, Year 2020.

\section{References}

[1] E. Hendriarianti, I. N. Sudiasa, and N. Karnaningroem, "Treatment Performance of Tlogomas Communal Waste Water Treatment Plant in Malang City", Journal of Applied 
Environmental and Biological Sciences, Vol. 5, No. 11, pp. 110-117, 2015.

[2] A. W. Mayo and E. E. Hanai, "Modeling phytoremediation of nitrogen-polluted water using water hyacinth (Eichhornia crassipes)", Physics and Chemistry of the Earth, Parts $A / B / C$, Vol. 100, pp. 170-180, 2017.

[3] S. Kumar, K. K. Dube, and J. P. N. Rai, "Mathematical model for phytoremediation of pulp and paper industry wastewater", Journal of Scientific \& Industrial Research, Vol. 64, pp. 717-721, 2005.

[4] L. Acero, "Phytoremediation of Phosphorous and Ammonia with Eichhornia crassipes and Azolla pinnata in Waste Waters from Estero de San Miguel Mendiola Manila Philippines", In: Proc. of E3S Web of Conf., Vol. 93, 2019.

[5] Z. Abbas, F. Arooj, S. Ali, I. E. Zaheer, M. Rizwan, and M. A. Riaz, "Phytoremediation of landfill leachate waste contaminants through floating bed technique using water hyacinth and water lettuce", International Journal of Phytoremediation, Vol. 21, pp. 1356-1367, 2019.

[6] E. Hendriarianti, C. D. Ratna, Reduction of Ammonia and Nitrate of WWTP Effluent using Phytoremediation, ITN Malang, Indonesia, Research Report, 2017.

[7] I. F. D. Ratnasari, S. N. Hadi, S. R. Suparto, O. Herliana, Y. R. Ahadiyat, "Phytoremediation of cadmium-contaminated soil using terrestrial kale (Ipomoea reptans Poir) and corncob biochar", Journal of Degraded and Mining Lands Management, Vol. 7, No. 4, pp. 23132318, 2020.

[8] M. Haghighi, M. Kafi, M. Pessarakli, A. Sheibanirad, and M. R. Sharifinia, "Using kale (Brassica oleracea var. acephala) as a phytoremediation plant species for lead $(\mathrm{Pb})$ and cadmium (Cd) removal in saline soils", Journal of Plant Nutrition, Vol. 39, pp. 1460-1471, 2016.

[9] J. Chua, J. M. Banua, I. Arcilla, A. Orbecido, M. E. de Castro, N. Ledesma, C. Deocaris, C. Madrazo, and L. Belo, "Phytoremediation potential and copper uptake kinetics of Philippine bamboo species in copper contaminated substrate", Heliyon, Vol. 5, 2019.

[10] S. Shyamala, N. A. Manikandan, K. Pakshirajan, V. T. Tang, E. R. Rene, H-S. Park, and S. K. Behera, "Phytoremediation of nitrate contaminated water using ornamental plants", Journal of Water Supply: Research and Technology-Aqua, Vol. 68, No. 8, pp. 731-743, 2019.

[11] I. T. A. Moreira, O. M. C. Oliveira, J. A. Triguis, A. M. P. dos Santos, A. F. S. Queiroz, C. M. S.
Martins, C. S. Silva, and R. S. Jesus, "Phytoremediation using Rizophora mangle L. in mangrove sediments contaminated by persistent total petroleum hydrocarbons (TPH's)", Microchemical Journal, Vol. 99, pp. 376-382, 2011.

[12] J. Emiliani, W. G. L. Oyarce, C. D. Bergara, L. M. Salvatierra, L. A.B. Novo, and L. M. Pérez, "Variations in the Phytoremediation Efficiency of Metal-polluted Water with Salvinia biloba: Prospects and Toxicological Impacts", Water, Vol. 12, No. 6, 2020.

[13] P. French, Real-Time Monitoring System for Phytoremediation Optimization, Final Report, SBIR Data Rights, ADA Technologies, Inc., Littleton, Colorado, 2006.

[14] L. Mabhungu, S. Newete, and E.M.I Adam, "Monitoring of phytoremediating wetland macrophytes using remote sensing in the case of common reed and giant reed: a review", Applied Ecology and Environmental Research, Vol. 17, No. 4, pp. 7957-7972, 2019.

[15] B. Humoreanu, and I. Nascu, "Wastewater treatment plant SCADA application", In: Proc. of 2012 IEEE International Conf. on Automation, Quality and Testing, Robotics, Cluj-Napoca, Romania, pp. 575-580, 2012.

[16] J. Wade, A. Sa'nchez, and M. R. Katebi, “On real-time control and process monitoring of wastewater treatment plants: real-time process monitoring", Transactions of the Institute of Measurement and Control, Vol. 27, No. 3, pp. 173-193, 2005.

[17] T. L. Mien and N. V. Tiem, "Design and implementation of the automatic waste water quality monitoring system of HPC factory", In: Proc. of 2019 International Conf. on Advanced Technologies for Communications (ATC), Hanoi, Vietnam, pp. 164-168, 2019.

[18] Y. E. Windarto, A. B. Prasetijo, and G. F. Damara, "A GIS-based Waste Water Monitoring System Using LoRa Technology", In: Proc. of 2018 5th International Conf. on Information Technology, Computer, and Electrical Engineering (ICITACEE), Semarang, Indonesia, pp. 176-179, 2018.

[19] A. Drenoyanis, R. Raad, I. Wady, and C. Krogh, "Wastewater Management: An IoT Approach", In: Proc. of 2018 IEEE Region Ten Symposium (Tensymp), Sydney, Australia, pp. 291-292, 2018.

[20] S. Rezwan, T. Ishtiak, R. Rahman, H. A. Rahman, M. Akter, H. A. Ratul, M. S. Hosain, and M. Jakariya, "A Minimalist Model of IoT based Sensor System for Sewage Treatment 
Plant Monitoring", In: Proc. of 2019 IEEE 10th Annual Information Technology, Electronics and Mobile Communication Conf. (IEMCON), Vancouver, BC, Canada, pp. 0939-0945, 2019.

[21] R. K. Kodali, S. C. Rajanarayanan, and S. Yadavilli, "IoT Monitoring Setup for Waste Water Treatment", In: Proc. of 2019 IEEE R10 Humanitarian Technology Conf. (R10-HTC) (47129), Depok, West Java, Indonesia, pp. 169$174,2019$.

[22] S. Aggarwal, R. Gulati, and B. Bhushan, "Monitoring of Input and Output Water Quality in Treatment of Urban Waste Water Using IOT and Artificial Neural Network", In: Proc. of 2019 2nd International Conf. on Intelligent Computing, Instrumentation and Control Technologies (ICICICT), Kannur, Kerala, India, pp. 897-901, 2019.

[23] https://thingspeak.com/

[24] R. Martínez, N. Vela, A. el Aatik, E. Murray, P. Roche, and J. M. Navarro, "On the Use of an IoT Integrated System for Water Quality Monitoring and Management in Wastewater Treatment Plants", Water, Vol. 12, 2020.

[25] E. Murray, P. Roche, K. Harrington, M. McCaul, B. Moore, A. Morrin, D. Diamond, B. Paull, "Low cost $235 \mathrm{~nm}$ ultra-violet light-emitting diode-based absorbance detector for application in a portable ion chromatography system for nitrite and nitrate monitoring", Journal of Chromatography A, Vol. 1603, pp. 8-14, 2019.

[26] D.Dovzan, V. Logar, and I. Skrjanc, "Implementation of an Evolving Fuzzy Model (eFuMo) in a Monitoring System for a WasteWater Treatment Process", IEEE Transactions on Fuzzy Systems, Vol. 23, No. 5, pp. 1761-1776, 2015.

[27] B. Mamandipoor, M. Majd, S. Sheikhalishahi, C. Modena, and V. Osmani, "Monitoring and detecting faults in wastewater treatment plants using deep learning", Environmental Monitoring and Assessment, Vol. 192, 2020.

[28] F. Harrou, A. Dairi, Y. Sun, M. Senouci, "Statistical monitoring of a wastewater treatment plant: A case study", Journal of Environmental Management, Vol. 223, pp. 807814, 2018.

[29] A. Soetedjo, I.B. Sulistiawati, "Implementing Discrete Model of Photovoltaic System on the Embedded Platform for Real-Time Simulation", Energies, Vol. 13, 2020.

[30] https://store.arduino.cc/usa/nano-33-iot

[31] https://www.mathworks.com/products/matlab.h tml 